In S. Trzcielinski and W. Karwowski (Eds.), 'Advances in Ergonomics in Manufacturing', Proceedings of the Fourth International Conference on Applied Human Factors and Ergonomics, AHFE 2012 (pp. 346-353). San Francisco, USA, 21-25 July, 2012: CRC Press.

\title{
Kitting as an information source in manual assembly
}

\author{
Anna Brolin ${ }^{1,2}$, Gunnar Bäckstrand ${ }^{1,3}$, Peter Thorvald ${ }^{1}$, Dan Högberg ${ }^{1}$, Keith Case Ka $^{1,2}$ \\ ${ }^{1}$ Virtual Systems Research Centre \\ University of Skövde \\ Skövde, Sweden \\ anna.brolin@his.se \\ ${ }^{2}$ Mechanical and Manufacturing Engineering \\ Loughborough University \\ Loughborough, United Kingdom \\ ${ }^{3}$ Research and Development \\ Swerea IVF \\ Stockholm, Sweden
}

\begin{abstract}
In manual assembly, a strategy to meet the goal of efficient production is the increased use of kitting as a material supply principle. Even though kitting is already implemented in industry, there are still uncertainties regarding the effects of introducing kits, particularly from a human factors perspective.

This paper presents initial steps in the development of a method to be used for the evaluation of kitting. This from an information source point of view and for studying effects related to productivity and quality. The methodology is projected to act as a foundation for how to carry out a subsequent comprehensive case study. The purpose of the case study is to explore how kitting affects the cognitive workload compared to the ordinary material rack combined with part numbers used in the current manufacturing industry. This is done by measuring productivity; time spent on assembling a product, and quality; number of assembly errors. One step in the methodology development process, which is described in this paper, was to conduct a pilot study, primarily to test the methodology related to the selection of measurement parameters, as well as for getting experiences from running the methodology with real test subjects.
\end{abstract}

Keywords: manual assembly, kitting, cognitive ergonomics, information use 


\section{INTRODUCTION}

In the automotive industry, well designed and presented information is vital for the assembly personnel to perform effective and accurate assembly operations. Unfortunately this is not the reality in many of the Swedish automotive plants. Due to increased customer demands and global competitiveness the companies have been forced to radically increase the product variation while at the same time becoming more efficient. This in turn has resulted in information overload (Sheridan, 2000; Wilson, 2001; Himma, 2007) that combined with stress, leads to an increased cognitive workload for the assembly workers (Bäckstrand, et al., 2005; Brolin, et al., 2011a).

One primary solution among current Swedish automotive manufacturers is the introduction of philosophies concerning standardisation of operations and eliminating waste throughout the entire production system, such as "The Toyota way" and "LEAN" (Liker, 2004). This has resulted in most of the factories also having developed a need to adapt methods and advanced technology to be able to support their staff in the work towards continuous improvement. However, the technology and methods already exist but due to insufficient knowledge, such as poorly thought out solutions and lack of understanding, the companies have invested in advanced equipment without understanding and investigating the workers' need.

A study was conducted at several Swedish automotive plants with the purpose of exploring which methods and equipment that was used to support the assembly personnel in performing the assembly task (Brolin, et al., 2011b). The observations showed investments such as pick-light, pick-voice, graphic displays, ordinary paper sheets and a material supply principle called kitting, which is currently used widely within the automotive industry. The kitting method was primarily introduced as a logistic tool, mostly due to the expansion of the material racks alongside of the assembly line. The use of kitting can be described as a way of presenting the assembler with a kit of components that together supports one or more assembly operations for a given product (Bozer \& McGinnis, 1992; Hanson \& Brolin, 2011). However, because of the assemblers' reasoning and experience the kit also functions as a carrier of information that complements or even replaces conventional assembly instructions. The benefit, from a cognitive ergonomics perspective, is that the assembler can focus on the assembly process, i.e. issues related to how to assemble, and strongly reduce the attention required for the decision process, i.e. issues related to what to assemble. Earlier studies have showed that a decreased cognitive workload can result in increased productivity and quality (Bäckstrand, 2009; Thorvald, 2011). This paper explores a method used to evaluate kitting from an information point of view and the kits possibility to increase productivity and quality.

The purpose of the case study is to explore how kitting affects the cognitive workload compared to the ordinary material rack combined with part numbers used in the current manufacturing industry. This is done by measuring productivity; time spent on assembling a product, and quality; number of assembly errors. One step in 
the methodology development process was to conduct a pilot study, primarily to test the methodology related to the selection of measurement parameters, as well as for getting experiences from running the methodology with real test subjects.

\section{METHOD}

The set up consisted of three differently arranged assembly stations where all of the assembly stations used the same assembly product, which contained 37 components (Figure 1). The study was carried out with 18 participants, all engineering staff and students, with three participants assembling simultaneously, one at each station. The two parameters that were explored in this study were productivity and quality.

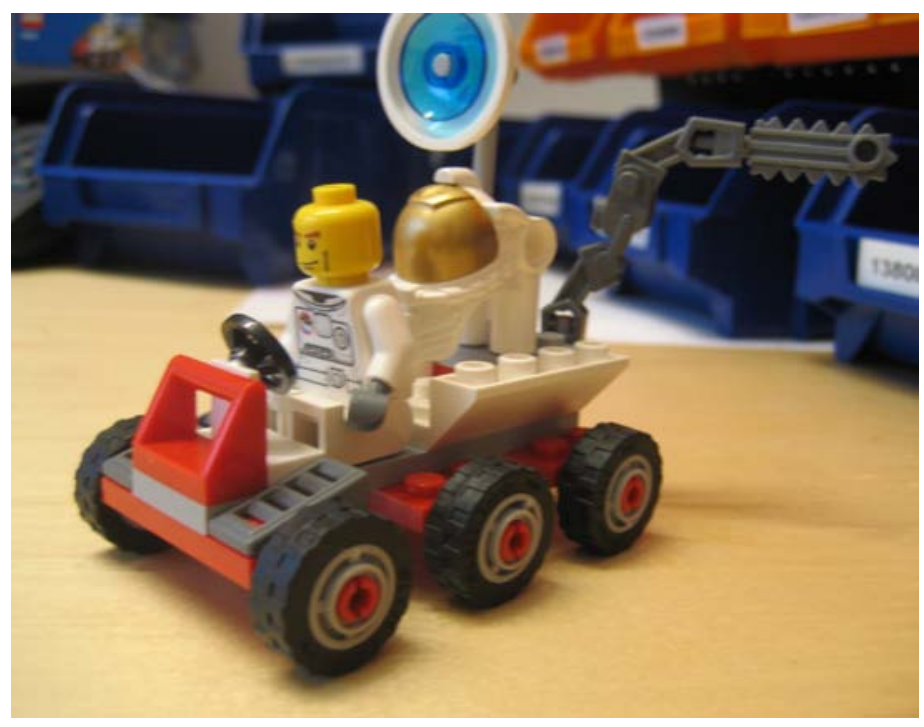

Figure 1. The assembly product - a LEGO car.

Workstation one emulated a traditional assembly station, presenting material through a material rack including several boxes with attached part numbers indicating a certain component (Figure 2). The material rack also contained components with associated part numbers that was not included in this assembly task, with the purpose to give a more accurate assembly situation as performed in manufacturing plants where product variants are common. 


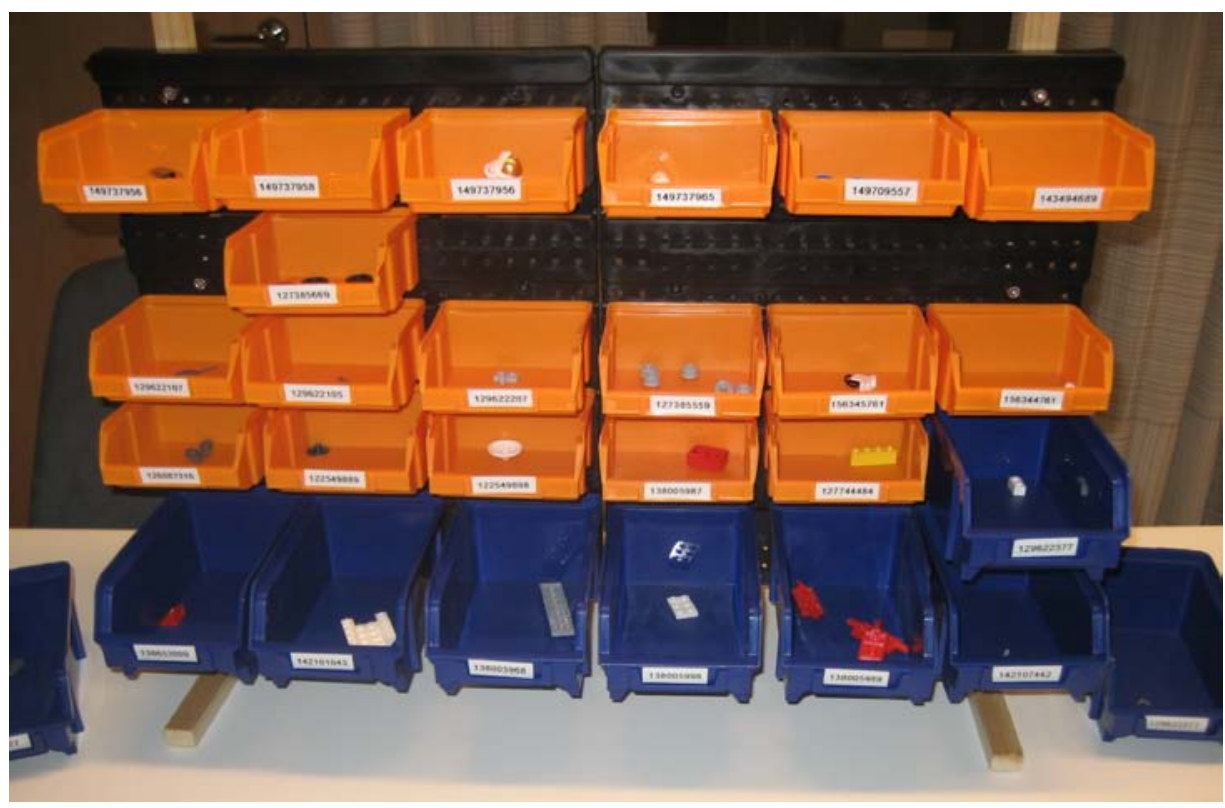

Figure 2. Workstation one - the industry look-a-like.

The assembly instruction for workstation one was illustrated in a traditional way, given on a paper sheet that contained the part numbers in a beforehand decided order for the assembly operation. The instruction included two pictures that showed the result of the assembled product.

Workstation two presented all the relevant components in one box, called an unstructured kit, and used step-by-step pictures as assembly instruction (Figure 3). This set of material presentation suggests that the assembler only has to search for components in one focused area. The instruction was influenced by LEGOinstructions that often are spoken of as clear and easy-to-use instructions. 


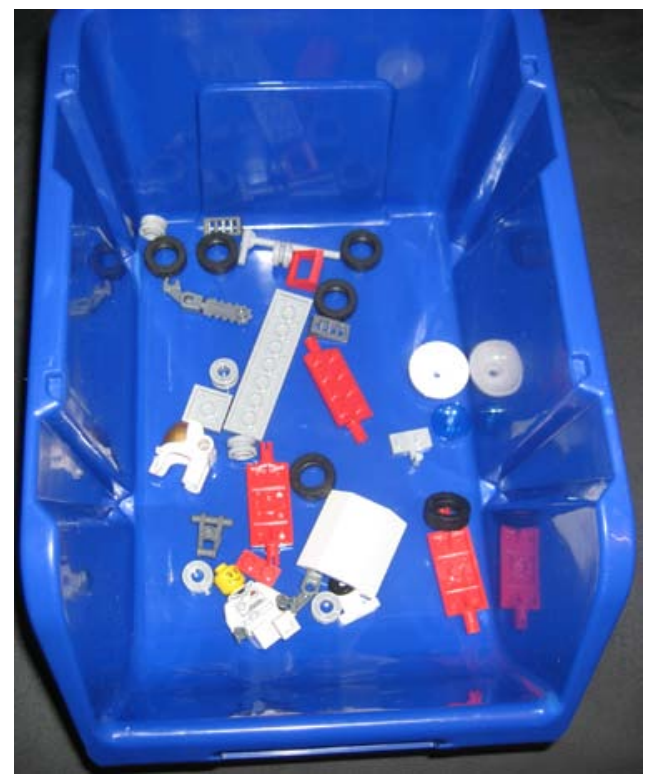

Figure 3. Unstructured kit as used in workstation two.

Workstation three used a similar setup as station two, presenting one box with all the relevant components. However, the box at this station contained separate sections where each component was placed in the same way as the assembly operation, a structured kit (Figure 4). The assembly instructions were the same as in workstation two, but included additional figures attached to the kitting box illustrating the direction of the assembly process.

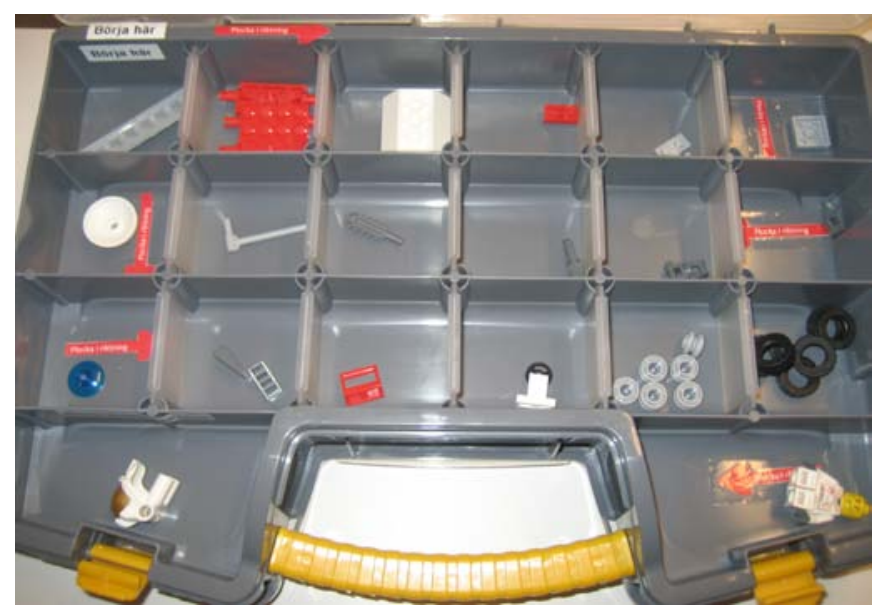

Figure 4. Structured kit as used in workstation three. 
The purpose of the pilot study was to evaluate if the forthcoming case study's experimental design was valid. The case study will follow the same structure; to compare material racks combined with part numbers towards unstructured and structured kits combined with additional step-by-step instructions.

\section{$3 \quad$ RESULTS}

The result showed the time it took for each participant to assemble the product (Table 1).

Table 1. Results of the pilot study.

\begin{tabular}{|c|c|c|c|c|c|c|c|c|}
\hline Workstation & \multicolumn{7}{|c|}{ Sets (minutes / assembled product) } \\
\hline & 1 & 2 & 3 & 4 & 5 & 6 & Sum & Average \\
\hline 1. Material rack & $*$ & $*$ & $*$ & $*$ & $*$ & $*$ & & \\
\hline 2. Unstructured kit & 2,37 & 3,27 & 4,51 & 8,31 & 3,27 & 4,32 & 26,05 & 4,42 \\
\hline 3. Structured kit & 2,54 & 4,27 & 2,33 & 2,06 & 4,00 & 2,55 & 17,75 & 2,96 \\
\hline
\end{tabular}

${ }^{\star}$ Did not assemble within reasonable time (> $\left.9 \mathrm{~min}\right)$

The pilot study indicates that how material is presented, and thereby information, is of great importance and influences productivity. Further, the few assembly errors indicate that the quality parameter is difficult to use, which shows that productivity should be the only measurement. These contemplations support the experimental design for the upcoming case study and therefore the study will continue.

\section{CONCLUSION AND DISCUSSION}

One conclusion, based on the results of the pilot study, is that quality cannot be used as a parameter, which was the initial idea. Having just a few assembly errors in the pilot study means that the forthcoming case study needs a tremendous amount of assembled products or a large amount of historic quality data that can be compared with the case study results. Since no previous data exists and there is an uncertainty towards getting a large amount of assembled products, the conclusion is to only use productivity as a measurable parameter. Other metrics that were not identified but had an unclear effect was for example time of day and assembly experience.

Stress is usually a common feature in manual assembly. In order to simulate this aspect during the pilot study, the instructor walked around between the workstations, constantly calling out the current time. The instructor then observed the difference in stress-level among the different workstation. The conclusion was 
that workstation one, using a material rack, was believed to possess the highest stress level which may be because the assembler is not receiving an overall view of the product and the assembly process due to poorly presented information. However, the stress level at workstation two and three seemed to be the same, situated on a fairly comfortable level.

Another interesting note was the assemblers' reaction after they all had finished the experiment. Each participant was faced towards the assembly object which meant that the participants were not able to see each other or other workstations during the experiment. Afterwards, when facing the other assemblers, the participants that had worked at the workstation with the material rack (station one) were all of the opinion that the other two workstations were perceived as easier. Also interesting is that until then, the participants assembling at station one were of the opinion that themselves were being slow, blaming themselves. Not reflecting on the poor information presented to the assembler.

This was also the case when participants from several Swedish automotive companies performed the pilot study at an industrial workshop. All participated in the study and displayed a great interest, which shows the urgency and importance of improving the productivity as well as the environment for the assembler.

In the forthcoming case study it has been decided that the case study will only study how assemblers handle product variants (i.e. products that differ in their components) and not process variants (i.e. products that are assembled differently but contain the same components). This is due to the argument that the process variants can be dealt with through professional development and training. The product variants on the other hand are harder to learn my heart (Bäckstrand, 2009). Of course it is possible to learn which component to choose for one particular product in a certain assembly situation. However, it is still well known that this can easily and quickly change in the automotive industry due to the arrival of new products and rebalancing of the assembly line, resulting in a quality risk.

\section{ACKNOWLEDGMENTS}

The authors would like to thank the participants that executed the pilot study as well as the workshop. This work has also been made possible with the support from Vinnova, Swedish Governmental Agency for Innovation Systems, which is gratefully acknowledged.

\section{REFERENCES}

Bozer, Y. A. \& McGinnis, L. F. (1992). Kitting versus line stocking: A conceptual framework and a descriptive model. International Journal of Production Economics, 28 (1), 1-19.

Brolin, A., Bäckstrand, G., Högberg, D. \& Case, K. (2011a). Inadequately designed information and its effect on the cognitive workload. In Proceedings of the 
International Manufacturing Conference, IMC 28, Institute of Technology, Dublin, Irland.

Brolin, A., Bäckstrand, G., Högberg, D. \& Case, K. (2011b). The use of k itting to ease assemblers' cognitive workload. In Nordic Ergonomic Society, Oulu, Finland. pp. 7782. Nordic Ergonimic Society.

Bäckstrand, G. (2009). Information Flow and Product Quality in Human Based Assembly. Loughborough University. Loughborough. Mechanical and Manufacturing Engineering.

Bäckstrand, G., de Vin, L. J., Högberg, D. \& Case, K. (2005). Parameters affecting quality in manual assembly of engines. In Proceedings of the International Manufacturing Conference, IMC 22, Institute of Technology, Tallaght, Dublin, August. pp. 165-172.

Hanson, R. \& Brolin, A. (2011). A comparison of kitting and continuous supply in in-plant materials supply. In The 4th International Swedish Production Symposium, Lund, Sweden. pp. 312-321.

Himma, K. E. (2007). The concept of i nformation overload: A preliminary step in understanding the nature of a harmful information-related condition. Ethics and Information Technology, 9 (4), 259-272.

Liker, J. K. (2004). The Toyota way: 14 management principles from the world's greatest manufacturer. McGraw-Hill Professional.

Sheridan, T. (2000). HCI in Supervisory Control: Twelve Dilemmas. In Elser, P. F., Kluwe, R. H. \& Boussoffara, B. (eds.). Human Error and System Design and Manufacturing. pp. 1-12: Springer-Verlag London Limited.

Thorvald, P. (2011). Presenting Information in Manual Assembly. Doctoral dissertation. Loughborough University. Loughborough. Mechanical and Manufacturing Engineering.

Wilson, T. D. (2001). Information Overload: Implications for Health-care Services. Health Informatics Journal, 7 (2), 112-117. 